\title{
Association of gender with outcomes in critically ill patients
}

Kamran Mahmood ${ }^{1 *}$, Kamal Eldeirawi ${ }^{2}$ and Momen M Wahidi ${ }^{1}$

\begin{abstract}
Introduction: The influence of gender on mortality and other outcomes of critically ill patients is not clear. Different studies have been performed in various settings and patient populations often yielding conflicting results. We wanted to assess the relationship of gender and intensive care unit (ICU) outcomes in the patients included in the Acute Physiology and Chronic Health Evaluation (APACHE) IV database (Cerner Corporation, USA).

Methods: We performed a retrospective review of the data available in the APACHE IV database. A total of 261,255 consecutive patients admitted to adult ICUs in United States from 1 January 2004 to 31 December 2008 were included. Readmissions were excluded from the analysis. The primary objective of the study was to assess the relationship of gender with ICU mortality. The secondary objective was to evaluate the association of gender with active therapy, mechanical ventilation, length of stay in the ICU, readmission rate and hospital mortality. The gender-related outcomes for disease subgroups including acute coronary syndrome, coronary artery bypass graft (CABG) surgery, sepsis, trauma and chronic obstructive pulmonary disease (COPD) exacerbation were assessed as well.
\end{abstract}

Results: ICU mortality was 7.2\% for men and 7.9\% for women, odds ratio (OR) for death for women was 1.07 (95\% confidence interval (Cl): 1.04 to 1.1). There was a statistically significant interaction between gender and age. In patients $<50$ years of age, women had a reduced ICU mortality compared with men, after adjustment for acute physiology score, ethnicity, co-morbid conditions, pre-ICU length of stay, pre-ICU location and hospital teaching status (adjusted OR $0.83,95 \%$ Cl: 0.76 to 0.91 ). But among patients $\geq 50$ years of age, there was no significant difference in ICU mortality between men and women (adjusted OR 1.02, 95\% Cl: 0.98 to 1.06).

A higher proportion of men received mechanical ventilation, emergent surgery, thrombolytic therapy and CABG surgery. Men had a higher readmission rate and longer length of ICU stay. The adjusted mortality of women compared to men was higher with CABG, while it was lower with COPD exacerbation. There was no significant difference in mortality in acute coronary syndrome, sepsis and trauma.

Conclusions: Among the critically ill patients, women less than 50 years of age had a lower ICU mortality compared to men, while 50 years of age or older women did not have a significant difference compared to men. Women had a higher mortality compared to men after CABG surgery and lower mortality with COPD exacerbation. There was no difference in mortality in acute coronary syndrome, sepsis or trauma.

\section{Introduction}

The association of gender with medical care outcomes is an area of intense interest. However, the studies evaluating this relationship in critically ill patients have reached inconsistent results. Some of these studies are large population-based cohorts, and it may be difficult to

\footnotetext{
* Correspondence: k.mahmood@duke.edu

'Department of Medicine, Division of Pulmonary, Allergy and Critical Care Medicine, Duke University Medical Center, DUMC 102356, Durham, NC 27710, USA

Full list of author information is available at the end of the article
}

apply these conclusions to critically ill patients [1]. Others have evaluated specific disease groups. There are some data to suggest that women have a delay in the diagnostic work up of coronary artery disease and do not receive appropriate and timely cardiac interventions [2-4]. The various outcomes after coronary artery bypass graft (CABG) surgery are worse for women as well [5-7]. The effect of gender on sepsis has varying results in different studies [8-17] while trauma mortality is similar in both men and women [18-21]. Men with chronic obstructive pulmonary disease (COPD) have been

\section{Biomed Central}


shown to have a higher mortality compared to women in some studies $[22,23]$ while others have found similar mortality rates [24]. At this time, however, there is no study on the association of gender with outcomes combining data from a large sample of critically ill patients with a variety of diagnoses from intensive care units (ICU) in the United States (US).

Studies from non-US ICUs have reached different conclusions regarding mortality based on gender, despite men receiving more aggressive care. Gender effects on outcomes in ICU patients in the US may be different from those in European and Canadian centers [25-27], as there are differences in the health care delivery systems. Hence, there is a need to study this issue in critically ill patients in the US.

The Acute Physiology and Chronic Health Evaluation (APACHE) IV database (Cerner Corporation, Kansas City, MO, USA) provides a unique opportunity to answer this question. The data include a large number of ICUs of different sizes, location and teaching status through out the US. It has information on diagnosis, acute physiology scores, age, comorbidities, race, source of patient admission (emergency room, floor, and so on), and time spent at the source. There are data on critical therapeutic interventions and pertinent outcomes, such as length of stay, duration of mechanical ventilation and ICU and hospital mortality [28].

The objective of this study was to evaluate the APACHE IV database for outcomes data regarding gender and diagnosis for a large cohort of critically ill patients. Our hypothesis was that female gender would confer a higher risk for mortality.

\section{Materials and methods}

We conducted a retrospective study of all adults in the APACHE IV database admitted to ICUs in the US between 1 January 2004 and 31 December 2008. Readmissions to the ICU were excluded from the analysis. The permission to access and utilize data was obtained from Cerner Corporation which supplied the data without any patient identifiers.

\section{Objectives}

The primary objective of this study was to evaluate the association of gender with ICU mortality. Secondary objectives included examining the association of gender with the need for active therapy during an ICU stay, the need and duration of mechanical ventilation, the readmission rate, the length of stay in the ICU and hospital mortality. We also assessed the association of gender with ICU mortality in disease subgroups including acute coronary syndrome, CABG surgery, sepsis, trauma and COPD exacerbation.

\section{Statistical analysis}

SAS version 9.1 (SAS Institute, Inc., Cary, NC, USA) was used for all statistical analyses. Univariate analyses were carried out to examine the differences between male and female patients as follows: continuous variables were assessed using Student's t-test and categorical variables were assessed using the Chi-square test. A two-tailed $P$-value of 0.05 or less was considered to indicate statistical significance.

For the analysis of ICU mortality, a multivariate logistic regression model was developed to control for potential confounding variables and to assess for interactions between gender and age. The following variables were included as potential covariates: acute physiology score (APS), age, ethnicity, select chronic health conditions, pre-ICU length of stay, pre-ICU location and hospital teaching status. Ethnicity included African-American, Hispanic and Caucasian while other races were excluded because of the low number of patients. We examined the presence of interaction between age $(<50$ years versus $\geq 50$ years) and gender in the logistic regression model. We found a statistically significant interaction between the two variables $(P<0.0001)$ and, therefore, we conducted the analyses stratified by age group: $<50$ and $\geq 50$ years of age, controlling for the above covariates. In addition, subsets of admission diagnoses including acute coronary syndrome (including acute myocardial infarction and unstable angina), CABG surgery, sepsis, trauma and COPD exacerbation, were studied individually to assess differences in outcomes based on gender.

Differences between genders in provision of aggressive critical care based on active treatment on the first day in the ICU, and other procedures, such as mechanical ventilation, thrombolytic therapy, pulmonary artery catheter placement, CABG and emergent surgery were also evaluated. Active treatment was defined as one of the thirty-three life saving interventions included in the Therapeutic Intervention Scoring System (TISS) which are unique to or best provided in an intensive care unit [29] and validated in clinical studies [15].

\section{Results}

Our cohort consisted of 261,255 consecutive admissions, of which 144,254 (55.2\%) were men and 117,001 (44.8\%) were women. Other characteristics of the cohort are shown in Table 1. In bivariate analyses, there were statistically significant differences between men and women on all tested variables but most of these differences were small and most likely due to the large sample size. Of note, there were considerably more men admitted post-operatively (39.7\%) than women (32.5\%), and men were on average younger (60.6 years) than women (63.1 years). 
Table 1 Baseline characteristics of the patients admitted to ICU.

\begin{tabular}{|c|c|c|c|}
\hline Baseline Characteristics & $\begin{array}{l}\text { Men } \\
\text { Number }=144,254\end{array}$ & $\begin{array}{l}\text { Women } \\
\text { Number }=117,001\end{array}$ & $P$-value for difference in means or proportions \\
\hline AGE (years) & 60.6 & 63.1 & $<0.0001$ \\
\hline RACE (\%) & & & $<0.0001$ \\
\hline Caucasian & 64.5 & 64.3 & \\
\hline African-American & 12.2 & 14.7 & \\
\hline Hispanic & 3.9 & 5.0 & \\
\hline Asian & 1.8 & 2.0 & \\
\hline American Indian & 0.2 & 0.2 & \\
\hline Other & 5.6 & 5.0 & \\
\hline Missing & 11.7 & 10.2 & \\
\hline \multicolumn{4}{|l|}{ COMORBID CONDITIONS (\%) } \\
\hline AIDS & 0.7 & 0.4 & $<0.0001$ \\
\hline Immunosuppression & 6.9 & 7.8 & $<0.0001$ \\
\hline Cirrhosis & 2.7 & 1.8 & $<0.0001$ \\
\hline Hepatic Failure & 1.5 & 1.1 & $<0.0001$ \\
\hline Non-Hodgkins' Lymphoma & 0.7 & 0.6 & 0.006 \\
\hline Leukemia and Multiple Myeloma & 1.1 & 0.9 & $<0.0001$ \\
\hline Tumor with metastases & 3.7 & 4.7 & $<0.0001$ \\
\hline ADMISSION DIAGNOSIS (\%) & & & $<0.0001$ \\
\hline Cardiovascular & 20.3 & 20.1 & \\
\hline Sepsis & 10.2 & 11.3 & \\
\hline Pulmonary & 7.9 & 10.3 & \\
\hline Gastrointestinal & 6.5 & 6.1 & \\
\hline Neurological & 9.9 & 11.8 & \\
\hline Surgical & 39.7 & 32.5 & \\
\hline Miscellaneous & 5.4 & 7.8 & \\
\hline LOCATION PRIOR TO ICU ADMISSION (\%) & & & $<0.0001$ \\
\hline Operating Room & 15.5 & 11.1 & \\
\hline Recovery Room & 18.3 & 19.9 & \\
\hline Emergency Room & 36.9 & 37.5 & \\
\hline Floor & 12.1 & 15.0 & \\
\hline ICU Transfer & 2.0 & 1.8 & \\
\hline Other Hospital & 6.1 & 5.9 & \\
\hline Direct Admission & 5.3 & 4.7 & \\
\hline Step Down Unit & 3.7 & 4.0 & \\
\hline Others & 0.1 & 0.1 & \\
\hline Pre-ICU Length of Stay (hours) & $1.6 \pm 5.4$ & $1.7 \pm 5.2$ & $<0.0001$ \\
\hline HOSPITAL TEACHING STATUS (\%) & & & $<0.0001$ \\
\hline COTH Member & 36.2 & 34.9 & \\
\hline Teaching Hospital, small & 35.9 & 35.8 & \\
\hline Nonteaching Hospital & 27.9 & 29.3 & \\
\hline
\end{tabular}

Continuous variables are compared using Student's t-test and categorical variables are compared using the Chi-square test. A $P$-value of 0.05 or less indicates statistical significance. $\mathrm{COTH}$, Council of Teaching Hospitals.

\section{ICU mortality}

ICU outcomes are shown in Table 2. ICU mortality was $7.2 \%$ for men and $7.9 \%$ for women (Figure 1), with an odds ratio (OR) of death for women of 1.07 (95\% confidence interval [CI]: 1.04 to 1.1, Table 3). However, after adjustment for APS, age, ethnicity, co-morbid conditions, pre-ICU length of stay, pre-ICU location and hospital teaching status, this relationship was not statistically significant (OR 0.98, 95\% CI: 0.95 to 1.02). There was a statistically significant interaction between gender and age (Figure 2). In stratified analyses, for patients $<50$ years of age, women had a lower mortality compared to men with the adjusted OR being 0.83 (95\% CI: 0.76 to 0.91 ). Among patients 50 years of age or older, there was no statistically significant difference in the ICU mortality between men and women, the 
Table 2 ICU outcomes.

\begin{tabular}{|c|c|c|c|}
\hline ICU Outcomes & $\begin{array}{l}\text { Men } \\
\text { Number }=144,254\end{array}$ & $\begin{array}{l}\text { Women } \\
\text { Number }=117,001\end{array}$ & $P$-value for difference in means or proportions \\
\hline ICU mortality (\%) & 7.2 & 7.9 & $<0.0001$ \\
\hline Hospital mortality (\%) & 11.8 & 12.9 & $<0.0001$ \\
\hline Mean APACHE IV & $50.3 \pm 26$ & $52.6 \pm 26$ & $<0.0001$ \\
\hline Mean APS & $39.1 \pm 24$ & $40.3 \pm 24$ & $<0.0001$ \\
\hline Active treatment day 1 (\%) & 62.5 & 60.4 & $<0.0001$ \\
\hline Mechanical ventilation (\%) & 40.1 & 37.9 & $<0.0001$ \\
\hline Time on ventilator (days) & $1.3 \pm 3.8$ & $1.2 \pm 3.8$ & $<0.0001$ \\
\hline Thrombolytic therapy (\%) & 1.3 & 0.7 & $<0.0001$ \\
\hline CABG (\%) & 6.5 & 3.1 & $<0.0001$ \\
\hline Emergent surgery (\%) & 7.2 & 6.2 & $<0.0001$ \\
\hline Readmission rate (\%) & 6.2 & 5.9 & 0.0005 \\
\hline ICU LOS (days) & $4.3 \pm 7.4$ & $4.1 \pm 6.8$ & $<0.0001$ \\
\hline Hospital discharge location (\%) & & & $<0.0001$ \\
\hline Home & 66.7 & 62.5 & \\
\hline Other Hospital & 5.8 & 5.6 & \\
\hline Hospice & 0.3 & 0.4 & \\
\hline Dead & 11.8 & 12.9 & \\
\hline LTAC/Chronic ventilator Facility & 0.03 & 0.04 & \\
\hline Skilled Nursing Facility & 8.4 & 11.4 & \\
\hline Rehabilitation Facility & 3.5 & 3.4 & \\
\hline Psychiatric Facility & 0.03 & 0.04 & \\
\hline Other & 2.5 & 2.6 & \\
\hline
\end{tabular}

Continuous variables are compared using Student's t-test and categorical variables are compared using the Chi-square test. A $P$-value of 0.05 or less indicates statistical significance. APACHE, Acute Physiology and Chronic Health Evaluation; APS, Acute physiology score; CABG, coronary artery bypass graft; LOS, length of stay; LTAC, long term acute care facility.

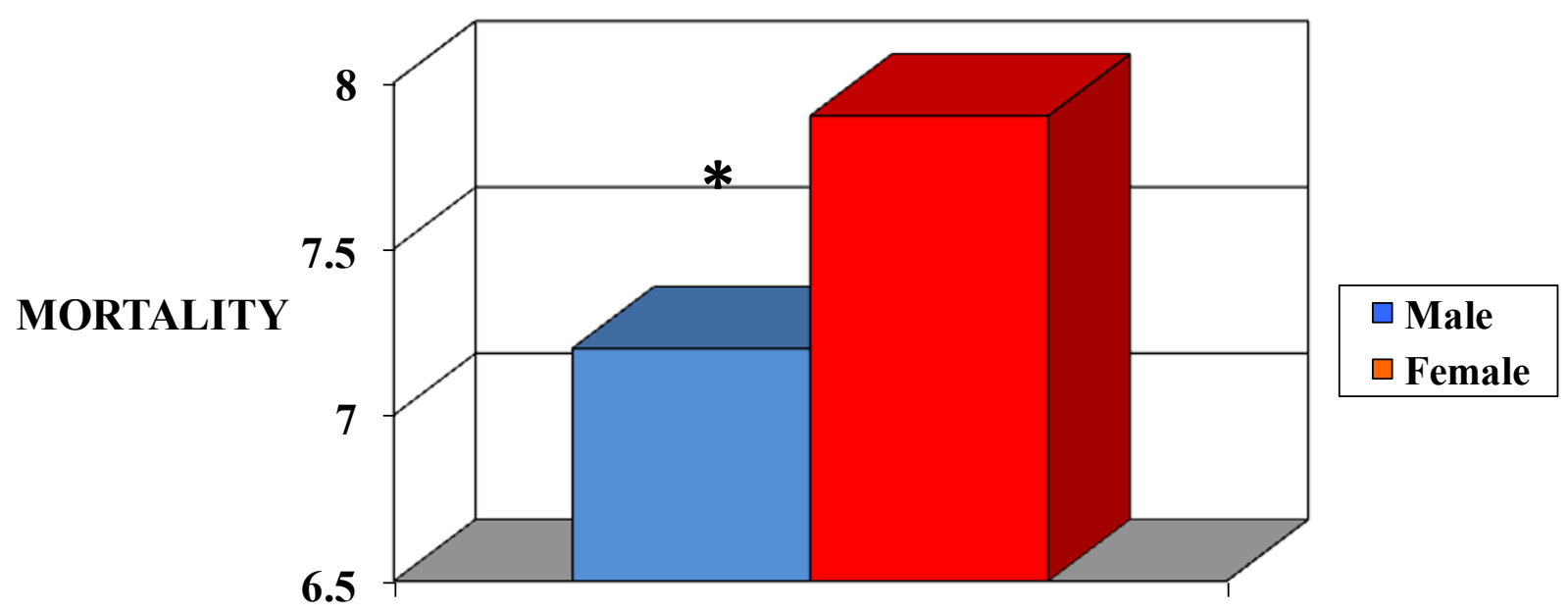

\section{GENDER}

\section{${ }^{*} P$-value for difference is $<0.0001$}


Table 3 Crude and adjusted odds ratio for mortality in ICU for women compared to men.

\begin{tabular}{|c|c|c|c|}
\hline ICU Outcomes & Mortality & 95\% Confidence Interval & $P$-value \\
\hline Crude mortality & 1.07 & 1.04 to 1.1 & $<0.0001$ \\
\hline Adjusted mortality ${ }^{a}$ & 0.98 & 0.95 to 1.02 & 0.39 \\
\hline Adjusted mortality for women $<50$ years ${ }^{b}$ & 0.83 & 0.76 to 0.91 & $<0.0001$ \\
\hline Adjusted mortality for women $\geq 50$ years ${ }^{\mathrm{b}}$ & 1.02 & 0.98 to 1.06 & 0.46 \\
\hline
\end{tabular}

${ }^{a}$ Adjusted for acute physiology score (APS), age, ethnicity, comorbid conditions, pre-ICU length of stay, pre-ICU location and hospital teaching status. ${ }^{b}$ Adjusted for APS, ethnicity, comorbid conditions, pre-ICU length of stay, pre-ICU location and hospital teaching status. Ethnicity includes African-American, Hispanic and Caucasian while other races were excluded because of the low percentage.

adjusted OR was 1.02 (95\% CI: 0.98 to 1.06$)$, as shown in Table 3.

\section{ICU interventions and outcomes}

Mean APACHE IV score on admission to ICU was 50.3 \pm 26 for men and $52.6 \pm 26$ for women $(P$-value $<0.0001)$, while mean APS was $39.1 \pm 24$ for men versus $40.3 \pm 24(P$-value $<0.0001)$ as shown in Table 2 . There was a statistically significant and higher proportion of men who received active treatment on ICU day 1: mechanical ventilation, pulmonary artery catheters (data not shown), thrombolytic therapy, coronary artery bypass graft and emergent surgery.

More men received mechanical ventilation $(40.1 \%$ versus $37.9 \%, P$-value $<0.0001)$ and they spent more time on the ventilator $(1.3 \pm 3.8$ days versus $1.2 \pm 3.8$ days, $P$-value $<0.0001)$. There was a higher readmission rate to the ICU for men, $6.2 \%$ versus $5.9 \%$ for women,
OR of readmission for women was 0.95 (95\% CI: 0.92 to 0.98$)$. ICU length of stay for men was $4.3 \pm 7.4$ days and for women was $4.1 \pm 6.8$ days ( $P$-value $<0.0001)$. Hospital mortality of men was $11.8 \%$ versus $12.9 \%$ for women.

\section{Subgroup analyses}

In additional subgroup analyses (Table 4), among patients who had CABG surgery, women were more likely to die than men (the adjusted OR for mortality: 1.80, $95 \%$ CI: 1.28 to 2.54 ). However, the mortality of women was significantly lower in the COPD exacerbation group (adjusted OR: 0.68, 95\% CI 0.53 to 0.87 ). There was no difference in the adjusted mortality of women with acute coronary syndrome (adjusted OR: 1.25, 95\% CI: 0.98 to .59), sepsis (adjusted OR: 1.07, 95\% CI: 0.99 to 1.16 ) and trauma (adjusted OR: $0.89,95 \% \mathrm{CI}$ : 0.76 to 1.04$)$.

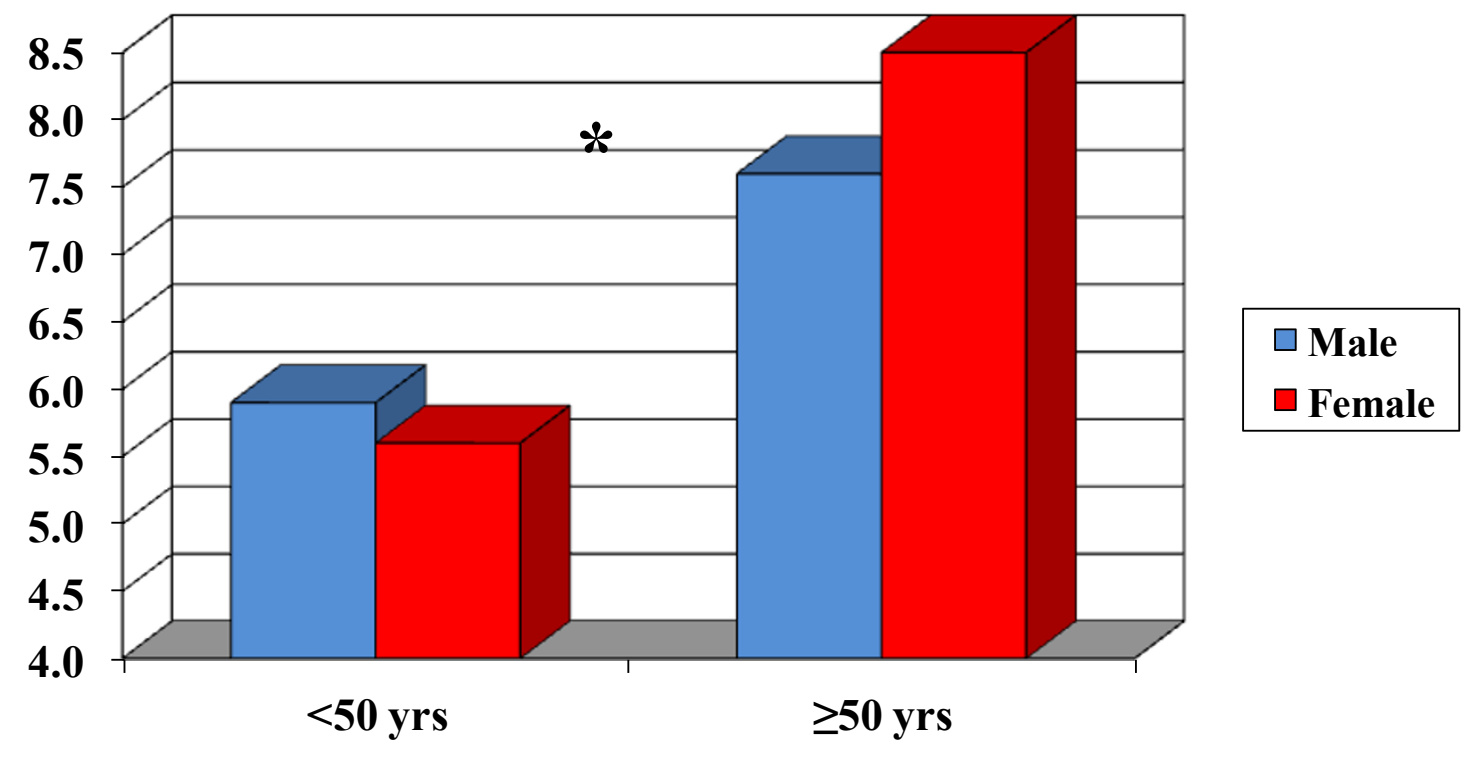

\section{* p-value for interaction is $<0.0001$}

Figure 2 Crude ICU mortality of gender groups based on age. 
Table 4 Adjusted ${ }^{a}$ odds ratio for mortality in ICU for women compared to men in diagnosis subgroups

\begin{tabular}{llll}
\hline Diagnosis Subgroups & Adjusted Mortality & $\mathbf{9 5 \%}$ Confidence Interval & $P$-value \\
\hline Acute Coronary Syndrome & 1.25 & 0.98 to 1.59 & 0.07 \\
CABG Surgery & 1.80 & 1.28 to 2.54 & 0.0004 \\
Sepsis & 1.07 & 0.99 to 1.16 & 0.08 \\
Trauma & 0.89 & 0.76 to .04 & 0.14 \\
COPD exacerbation & 0.68 & 0.53 to 0.87 & 0.002 \\
\hline
\end{tabular}

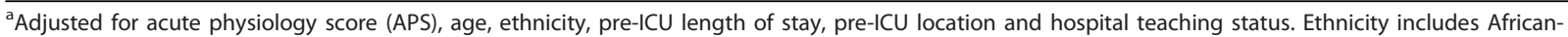
American, Hispanic and Caucasian while other races were excluded because of the low percentage. CABG, coronary artery bypass graft; COPD, chronic obstructive pulmonary disease.

\section{Discussion}

In this analysis of large number of critically ill patients included in the APACHE IV database, the crude ICU mortality was higher for women compared to men. However, there was a significant interaction between gender and age. Since there were differences between men and women in severity of illness, ethnicity, comorbid conditions, pre-ICU length of stay, pre-ICU location and hospital teaching status, we controlled for these covariates. The adjusted mortality of women $<50$ years was lower compared to men while it was similar in patients $\geq 50$ years of age. In the subgroup analysis, the adjusted mortality of women was higher after CABG and lower for COPD exacerbation. The adjusted mortality was similar for acute coronary syndrome, sepsis and trauma.

Our results are similar to Valentin et al. who studied a cohort of patients in Austrian ICUs [25]. They found similar illness adjusted mortality in men and women, despite men receiving an increased level of care. Fowler et al. also found a disparity in ICU care in favor of men, with an increased adjusted mortality in older women in Canadian ICUs [26]. In a Belgian retrospective study, Romo et al. concluded that women $>50$ years old had a higher mortality compared to men, while pre-menopausal women failed to show any survival benefit compared to men [27]. Our study is different from these studies as the women younger than 50 years had a lower adjusted ICU mortality, while it was not different in the older women. In our cohort, the APACHE IV and APS were higher in women but more men received active treatment in the ICU, including mechanical ventilation, emergent surgery, thrombolytics and CABG. They stayed longer on the ventilator and in the ICU, and had a higher readmission rate as well.

The age based difference in mortality can be explained on the basis of hormonal theory. Several laboratory studies have shown beneficial effects of estrogen. Estrogen preserves the cardiovascular and immunological function $[30,31]$ and tolerance to severe hypoxia, while $5 \alpha$ dihydrotestosterone (DHT) suppresses these functions. Immune responses are more vigorous in women, with greater antibody production and cell mediated immunity after immunization [32]. In an experimental model of Eschericia coli lipopolysaccharide administration, females have a greater pro-inflammatory response and norepinephrine sensitivity [33]. Hormonal manipulation in animal models reduces the sepsis related mortality in males. In a hemorrhagic shock model, female rodents have preserved splenocyte function and IL-3 secretion, along with IL-1 secretion by macrophages, in contrast to male rodents [34]. Ovariectomized rodents lose this advantage, which is later regained by administration of $17 \beta$-estradiol [35]. Estrogens reduce the chemotaxis and activation of neutrophils and reduce pulmonary injury following hemorrhagic shock [36]. Administration of estrogen receptor- $\beta$ agonist preserves gastrointestinal mucosal barrier function and improves outcome in a rodent model of sepsis [37]. $17 \beta$-estradiol-treated males have diminished cardiomyocyte IL- 6 production and improved cardiac function [38]. Despite this large accumulation of laboratory evidence on the beneficial effect of estrogens and deleterious effects of testosterone, conclusive evidence in clinical settings is not seen.

Our study showed significantly higher mortality in women after CABG compared to men while mortality in women with an acute coronary event was similar to men in multivariate analysis. Several studies have shown that the outcomes of women after CABG are worse than men, including mortality, duration of mechanical ventilation, length of stay in the ICU and hospital, and some long-term outcomes [5-7]. However, some of the later studies have attributed this to the severity of illness and co-morbidities in women [39-41]. In one study, increased mortality in women after CABG was attributed to infection [42]. Get with the Guidelines-Coronary Artery Database investigators reported no overall difference in mortality between men and women with acute myocardial infarction. However, ST-elevation myocardial infarction mortality was higher in women and there was an underuse of evidence-based therapy and a delay in therapeutic interventions [2]. Similar results have been reported by other researchers $[3,4,43]$.

Women with sepsis had a similar adjusted mortality compared to men in our study. This is in agreement with several studies. In a large cohort of 192,980 
patients with severe sepsis, Angus et al. concluded that there was no difference in mortality between men and women after adjusting for age, underlying comorbidities and the site of infection [8]. Martin et al. in a large epidemiologic study of the US population from 1979 to 2000 found that sepsis was more common in men (annual relative risk 1.28; CI: 1.24 to 1.32 ). However, they also did not find a difference in mortality in men versus women (22\% versus $21.8 \%$ ) [1]. Several other studies reported similar mortality in both genders [9-11] while others have reported a lower mortality for women [12-14]. In a recent prospective study, Nachtigall and colleagues found a significantly higher mortality for women admitted to the ICU with sepsis while the infection-related care was similar in both the genders [15]. In another study, female patients in the ICU with nosocomial infections had a higher mortality, after controlling for variables including age, severity score, immunocompromised status and admission source [16]. Eachempati and colleagues found that there was a higher mortality in elderly critically ill female surgical patients with sepsis [17]. The difference in outcomes in various studies can perhaps be explained on the basis of different care settings and the innate characteristics of the cohorts. A study has shown that an elevated level of $17 \beta$-estradiol in both genders, increased progesterone in men and elevated testosterone in women is associated with worse survival [44]. However, we do not have any hormonal data available for our cohort.

We found no difference in mortality between the genders admitted with trauma. In a retrospective study by Magnotti and colleagues, there was no difference in mortality after blunt trauma between the genders, but men had a higher morbidity [18]. No difference in mortality was found in several other studies as well [19-21].

The current study showed decreased adjusted mortality in women compared to men admitted with a diagnosis of COPD exacerbation to the ICU. This conclusion is in line with several studies [22,23]. However, Celli and colleagues found that women who participated in the Toward a Revolution in COPD Health (TORCH) study had a lower mortality than men but this difference was not statistically significant after adjustment for important covariates including airflow obstruction and body mass index [24]. Our difference from the TORCH study could be explained on the basis that later excluded patients with significant comorbidities and long-term oxygen therapy.

The current study has several strengths. First, the study has a large sample size of critically ill patients from different demographics and with a wide array of diagnoses. Second, the data used came from a variety of hospitals with different sizes, teaching status, ICU coverage and geographic locations. Thus, the results of the study are generalizable. The weaknesses include a retrospective design that precludes from leading to any definitive conclusions. We cannot rule out other interactions and confounders such as hospital admission time, ICU staffing and so on that may play a role in the observed differences. It is also not clear why men have similar mortality compared to women, despite a trend towards getting more aggressive care. The differences in some of the ICU outcomes including mortality are statistically significant but may be of small magnitude to hold any clinical consequence. It is also possible that these results may be typical for ICUs that use the APACHE IV system and may not be applicable to other institutions. However, this study presents a snapshot of the current critical care practice in the United States.

\section{Conclusions}

This study shows that women younger than 50 years of age had a lower ICU mortality compared to men, after adjustment for covariates. On the other hand, women 50 years of age or older had an adjusted ICU mortality similar to men. There was a higher mortality of women admitted after CABG. However, the mortality of women admitted with COPD exacerbation was less compared to the men. There was no difference in the adjusted mortality between genders with acute coronary syndrome, sepsis and trauma.

\section{Key messages}

- The younger women ( $<50$ years old) admitted to intensive care unit had lower adjusted mortality compared to men, while mortality was similar in older patients.

- Women had higher ICU mortality with CABG surgery and lower ICU mortality with COPD exacerbation compared to men, after adjustment for several clinically important covariates. There was no difference between men and women in adjusted ICU mortality after acute coronary syndrome, sepsis and trauma.

\section{Abbreviations}

APACHE: Acute Physiology and Chronic Health Evaluation; APS: Acute

Physiology Score; CABG: coronary artery bypass graft; Cl: confidence interval; COPD: chronic obstructive pulmonary disease; DHT: 5 a-dihydrotestosterone; COTH: Council of Teaching Hospitals; LTAC: long term acute care facility.

\section{Acknowledgements}

Special thanks to Andrew A. Kramer, PhD, Cerner Corporation, Vienna, VA, and Scott Shofer MD, PhD, Duke University Medical Center, Durham, NC who helped with the study design and manuscript revision. Special thanks to Cerner Corporation, Kansas City, Missouri, USA, who provided the data from the APACHE IV database.

\section{Author details}

${ }^{1}$ Department of Medicine, Division of Pulmonary, Allergy and Critical Care Medicine, Duke University Medical Center, DUMC 102356, Durham, NC 
27710, USA. ${ }^{2}$ Department of Health Systems Science, College of Nursing (M/ C 802), University of Illinois at Chicago, 845 S Damen Ave, Room 1054, Chicago, IL 60612, USA.

\section{Authors' contributions}

KM was responsible for study design, interpretation of data and analysis, and manuscript writing. He takes full responsibility for the integrity of the study. KE was responsible for study design, data analysis, and manuscript revision. MMW was responsible for study design and manuscript revision. All authors read and approved the final manuscript.

\section{Competing interests}

The authors declare that they have no competing interests.

Received: 13 January 2012 Revised: 1 April 2012

Accepted: 22 May 2012 Published: 22 May 2012

\section{References}

1. Martin GS, Mannino DM, Eaton S, Moss M: The epidemiology of sepsis in the United States from 1979 through 2000. N Engl J Med 2003, 348:1546-1554.

2. Ineid H, Fonarow GC, Cannon CP, Hernandez AF, Palacios IF, Maree AO, Wells Q, Bozkurt B, Labresh KA, Liang L, Hong Y, Newby LK, Fletcher G, Peterson E, Wexler L: Get With the Guidelines Steering Committee and Investigators. Sex differences in medical care and early death after acute myocardial infarction. Circulation 2008, 118:2803-2810.

3. Halvorsen S, Eritsland J, Abdelnoor M, Holst Hansen C, Risøe C, Midtbø K, Bjørnerheim R, Mangschau A: Gender differences in management and outcome of acute myocardial infarctions treated in 2006-2007. Cardiology 2009, 114:83-88.

4. Heer T, Gitt AK, Juenger C, Schiele R, Wienbergen H, Towae F, Gottwitz M, Zahn R, Zeymer U, Senges J, ACOS Investigators: Gender differences in acute non-ST-segment elevation myocardial infarction. Am J Cardiol 2006, 98:160-166.

5. Butterworth J, James R, Prielipp R, Cerese J, Livingston J, Burnett D: Female gender associates with increased duration of intubation and length of stay after coronary artery surgery. CABG clinicalbBenchmarking database participants. Anesthesiology 2000, 92:414-424.

6. Wong DT, Cheng DC, Kustra R, Tibshirani R, Karski J, Carroll-Munro J, Sandler A: Risk factors of delayed extubation, prolonged length of stay in the intensive care unit, and mortality in patients undergoing coronary artery bypass graft with fast-track cardiac anesthesia: a new cardiac risk score. Anesthesiology 1999, 91:936-944.

7. Hassan A, Chiasson M, Buth K, Hirsch G: Women have worse long-term outcomes after coronary artery bypass grafting than men. Can J Cardiol 2005, 21:757-762.

8. Angus DC, Linde-Zwirble WT, Lidicker J, Clermont G, Carcillo J, Pinsky MR: Epidemiology of severe sepsis in the United States: analysis of incidence, outcome, and associated costs of care. Crit Care Med 2001, 29:1303-1310.

9. Esper AM, Moss M, Lewis CA, Nisbet R, Mannino DM, Martin GS: The role of infection and comorbidity: factors that influence disparities in sepsis. Crit Care Med 2006, 34:2576-2582

10. Crabtree TD, Pelletier SJ, Gleason TG, Pruett TL, Sawyer RG: Genderdependent differences in outcome after the treatment of infection in hospitalized patients. JAMA 1999, 282:2143-2148.

11. Wichmann MW, Inthorn D, Andress HJ, Schildberg FW: Incidence and mortality of severe sepsis in surgical intensive care patients: the influence of patient gender on disease process and outcome. Intensive Care Med 2000, 26:167-172.

12. Adrie C, Azoulay E, Francais A, Clec'h C, Darques L, Schwebel C, Nakache D, Jamali S, Goldgran-Toledano D, Garrouste-Orgeas M, Timsit JF, OutcomeRea Study Group: Influence of gender on the outcome of severe sepsis: a reappraisal. Chest 2007, 132:1786-1793.

13. Schröder J, Kahlke V, Staubach KH, Zabel P, Stüber F: Gender differences in human sepsis. Arch Surg 1998, 133:1200-1205.

14. Melamed A, Sorvillo FJ: The burden of sepsis-associated mortality in the United States from 1999 to 2005: an analysis of multiple-cause-of-death data. Crit Care 2009, 13:R28.

15. Nachtigall I, Tafelski S, Rothbart A, Kaufner L, Schmidt M, Tamarkin A, Kartachov M, Zebedies D, Trefzer T, Wernecke KD, Spies C: Gender-related outcome difference is related to course of sepsis on mixed ICUs: a prospective, observational clinical study. Crit Care 2011, 15:R151.

16. Combes A, Luyt CE, Trouillet JL, Nieszkowska A, Chastre J: Gender impact on the outcomes of critically ill patients with nosocomial infections. Crit Care Med 2009, 37:2506-2511.

17. Eachempati SR, Hydo L, Barie PS: Gender-based differences in outcome in patients with sepsis. Arch Surg 1999, 134:1342-2347.

18. Magnotti $L$, Fischer PE, Zarzaur BL, Fabian TC, Croce MA: Impact of gender on outcomes after blunt injury: a definitive analysis of more than 36,000 trauma patients. J Am Coll Surg 2008, 206:984-991.

19. Croce MA, Fabian TC, Malhotra AK, Bee TK, Miller PR: Does gender difference influence outcome? J Trauma 2002, 53:889-894.

20. Napolitano LM, Greco ME, Rodriguez A, Kufera JA, West RS, Scalea TM: Gender differences in adverse outcomes after blunt trauma. J Trauma 2001, 50:274-280.

21. Rappold JF, Coimbra R, Hoyt DB, Potenza BM, Fortlage D, Holbrook T, Minard G: Female gender does not protect blunt trauma patients from complications and mortality. J Trauma 2002, 53:436-441.

22. Gonzalez AV, Suissa S, Ernst P: Gender differences in survival following hospitalisation for COPD. Thorax 2011, 66:38-42.

23. Meyer PA, Mannino DM, Redd SC, Olson DR: Characteristics of adults dying with COPD. Chest 2002, 122:2003-2008.

24. Celli B, Vestbo J, Jenkins CR, Jones PW, Ferguson GT, Calverley PM, Yates JC, Anderson JA, Willits LR, Wise RA, on behalf of the investigators of the TORCH study: Gender differences in mortality and clinical expressions of patients with COPD: the TORCH experience. Am J Respir Crit Care Med 2011, 183:317-322

25. Valentin A, Jordan B, Lang T, Hiesmayr M, Metnitz PG: Gender-related differences in intensive care: a multiple-center cohort study of therapeutic interventions and outcome in critically ill patients. Crit Care Med 2003, 31:1901-1907

26. Fowler RA, Sabur N, Li P, Juurlink DN, Pinto R, Hladunewich MA, Adhikari NK, Sibbald WJ, Martin CM: Sex-and age-based differences in the delivery and outcomes of critical care. CMAJ 2007, 177:1513-1519.

27. Romo $H$, Amaral AC, Vincent $J$ : Effect of patient sex on intensive care unit survival. Arch Intern Med 2004, 164:61-65.

28. Zimmerman JE, Kramer AA, McNair DS, Malila FM: Acute physiology and chronic health evaluation (APACHE) IV: hospital mortality assessment for today's critically ill patients. Crit Care Med 2006, 34:1297-1310.

29. Zimmerman JE, Kramer AA: A model for identifying patients who may not need intensive care unit admission. J Crit Care 2010, 25:205-213.

30. Choudhry MA, Bland KI, Chaudry $\mid \mathrm{H}$ : Gender and susceptibility to sepsis following trauma. Endocr Metab Immune Disord Drug Targets 2006, 6:127-135

31. Sperry JL, Minei JP: Gender dimorphism following injury: making the connection from bench to bedside. J Leukoc Biol 2008, 83:499-506.

32. Whitacre CC, Reingold SC, O'Looney PA: A gender gap in autoimmunity. Science 1999, 283:1277-1278.

33. van Eijk LT, Dorresteijn MJ, Smits P, van der Hoeven JG, Netea MG, Pickkers P: Gender differences in the innate immune response and vascular reactivity following the administration of endotoxin to human volunteers. Crit Care Med 2007, 35:1464-1469.

34. Zellweger R, Wichmann MW, Ayala A, Stein S, DeMaso CM, Chaudry $\mathrm{H}$ : Females in proestrus state maintain splenic immune functions and tolerate sepsis better than males. Crit Care Med 1997, 25:106-110.

35. Knöferl MW, Jarrar D, Angele MK, Ayala A, Schwacha MG, Bland KI, Chaudry $\mathrm{H}$ : 17 beta-Estradiol normalizes immune responses in ovariectomized females after trauma-hemorrhage. Am J Physiol Cell Physiol 2001, 281:C1131-1138.

36. Miyagi M, Aoyama H, Morishita M, Iwamoto Y: Effects of sex hormones on chemotaxis of human peripheral polymorphonuclear leukocytes and monocytes. J Periodontol 1992, 63:28-32.

37. Cristofaro PA, Opal SM, Palardy JE, Parejo NA, Jhung J, Keith JC Jr, Harris HA: WAY-202196, a selective estrogen receptor-beta agonist, protects against death in experimental septic shock. Crit Care Med 2006, 34:2188-2193.

38. Yang S, Zheng R, Hu S, Ma Y, Choudhry MA, Messina JL, Rue LW 3rd, Bland $\mathrm{Kl}$, Chaudry $\mathrm{IH}$ : Mechanism of cardiac depression after traumahemorrhage: increased cardiomyocyte IL- 6 and effect of sex steroids on IL-6 regulation and cardiac function. Am J Physiol Heart Circ Physiol 2004, 287:H2183-2191 
39. Toumpoulis IK, Anagnostopoulos CE, Balaram SK, Rokkas CK, Swistel DG, Ashton RC Jr, DeRose JJ Jr: Assessment of independent predictors for long-term mortality between women and men after coronary artery bypass grafting: are women different from men? I Thorac Cardiovasc Surg 2006, 131:343-351.

40. Koch CG, Weng YS, Zhou SX, Savino JS, Mathew JP, Hsu PH, Saidman LJ, Mangano DT, Ischemia Research and Education Foundation, Multicenter Study of Perioperative Ischemia Research Group: Prevalence of risk factors, and not gender per se, determines short- and long-term survival after coronary artery bypass surgery. J Cardiothorac Vasc Anesth 2003, 17:585-593.

41. Cartier R, Bouchot O, El-Hamamsy I: Influence of sex and age on longterm survival in systematic off-pump coronary artery bypass surgery. Eur J Cardiothorac Surg 2008, 34:826-832.

42. Rogers MA, Langa KM, Kim C, Nallamothu BK, McMahon LF Jr, Malani PN, Fries BE, Kaufman SR, Saint S: Contribution of infection to increased mortality in women after cardiac surgery. Arch Intern Med 2006, 166:437-443.

43. Lansky AJ, Mehran R, Cristea E, Parise H, Feit F, Ohman EM, White HD, Alexander KP, Bertrand ME, Desmet W, Hamon M, Stone GW: Impact of gender and antithrombin strategy on early and late clinical outcomes in patients with non-ST-elevation acute coronary syndromes (from the ACUITY trial). Am J Cardiol 2009, 103:1196-1203.

44. Angstwurm MW, Gaertner R, Schopohl J: Outcome in elderly patients with severe infection is influenced by sex hormones but not gender. Crit Care Med 2005, 33:2786-2793.

\section{doi:10.1186/CC11355}

Cite this article as: Mahmood et al: Association of gender with outcomes in critically ill patients. Critical Care 2012 16:R92.

\section{Submit your next manuscript to BioMed Central} and take full advantage of:

- Convenient online submission

- Thorough peer review

- No space constraints or color figure charges

- Immediate publication on acceptance

- Inclusion in PubMed, CAS, Scopus and Google Scholar

- Research which is freely available for redistribution

Submit your manuscript at www.biomedcentral.com/submit
Biomed Central 